\title{
SCIDoC
}

\author{
International Journal of Dentistry and Oral Science (IJDOS) \\ ISSN: 2377-8075
}

\section{Assessment Of Immunomodulatory Effect Of Natural Antioxidants - An In Vitro Study}

Research Article

Manivasagam Deepigaa ${ }^{1}$, Muthukrishnan Arvind ${ }^{2 *}$, S Rajeshkumar ${ }^{3}$

${ }^{1}$ Post Graduate Resident, Department of Oral medicine and Radiology, Saveetha Dental College and Hospitals, Saveetha Institute of Medical and Technical sciences(SIMATS), Saveetha University, Chennai, India.

${ }^{2}$ Professor and Head, Department of Oral Medicine and Radiology, Saveetha Dental College and Hospitals, Saveetha Institute of Medical and Technical sciences(SIMATS), Saveetha University, Chennai, India.

${ }^{3}$ Associate Professor, Nanobiomedicine Lab, Department of Pharmacology, Saveetha Dental College and Hospitals, Saveetha Institute of Medical and Technical sciences(SIMATS), Saveetha University, Chennai, India.

Abstract

\begin{abstract}
Aim: To prepare herbal formulation of garlic, turmeric, honey and spirulina and analyse its immunomodulatory effect. Garlic has anti allergic, antitumor effects and chemopreventive effects.Turmeric has analgesic, anti-inflammatory, wound healing and immunomodulatory activities. Spirulina has antioxidant, immunomodulatory, anti-inflammatory, anticancer, anti-viral, and antibacterial effects. Honey has antimicrobial, antioxidant, anticancer, anti-inflammatory.

Materials and methods: Garlic, turmeric, honey and spirulina were mixed with $100 \mathrm{ml}$ of distilled water and boiled for 15 minutes, filtered and again concentrated to $5 \mathrm{ml}$. The immunomodulatory effect was assessed by diphenyl 1-picryl- hydrazylhydrate assay (DPPH), Ferric reducing antioxidant power assay (FRAP) and $\mathrm{H} 2 \mathrm{O} 2$ assay.

Results: The prepared extract showed significant results at 501 when assessed using DPPH, FRAP and H2O2 assay (i.e) $72.1 \%, 94.6 \%$ and $67.9 \%$ respectively.

Conclusion: This study shows the combination of Garlic, turmeric, honey and spirulina formulation have good immunomodulatory effects when compared to the standard. Hence in future it can be used as a safe alternative instead of commercially available medicines in the form of in-situ gel for management of immune mediated disorders.
\end{abstract}

Keywords: Garlic; Turmeric; Honey; Spirulina; Antioxidant; Immunomodulator.

\section{Introduction}

Immunomodulation refers to alteration in immune response which either decreases or increases the immune responsiveness. Immunostimulation is enhancement of immune responsiveness while immunosuppression is reduction of immune responsiveness. A substance which stimulates, suppresses or modulates any of the components of the immune system including both innate and adaptive arms of the immune response are termed as immunomodulators [1]. The essence of immunomodulation depends on the immunomodulating effect of pharmacological agents acting under various doses and time [2, 3]. Majorly used immunomodulators are natural adjuvants, synthetic agents, antibody reagents. As they have generalized effects throughout the immune system a lot of adverse effects have been reported [4]. In order to overcome the side effects a large number of drugs from natural sources either herbal or minerals have been used as an alternative to alter the human immune system [5]. There are several natural products which are employed in different systems of medicine throughout the world to improve the immunological disorders. Successful use of plant products in management of various conditions can be traced back to $6000 \mathrm{BC}$ in India $[4,6]$.

Allium sativum (Garlic) which is an essential dietary component cultivated majorly in India, and commonly known as garlic worldwide. Some evidence for immunomodulatory effects of garlic have been reported in in vitro and in vivo studies which showed increased T-lymphocyte blastogenesis and phagocytosis, as well

\section{*Corresponding Author}

Muthukrishnan Arvind,

Professor and Head, Department of Oral Medicine and Radiology, Saveetha Dental College and Hospitals, Saveetha Institute of Medical and Technical sciences(SIMATS), Saveetha

University, Chennai, India.

Tel: 9444303303

E-mail: arvindm@saveetha.com

Received: April 18, 2021

Accepted: September 20, 2021

Published: September 21, 2021

Citation: Manivasagam Deepigaa, Muthukrishnan Arvind, S Rajeshkumar. Assessment Of Immunomodulatory Effect Of Natural Antioxidants - An In Vitro Study. Int J Dentistry Oral Sci. 2021;8(9):4423-4427. doi: http://dx.doi.org/10.19070/2377-8075-21000901

Copyright: Muthukrishnan Arvind ${ }^{\circ} 2021$. This is an open-access article distributed under the terms of the Creative Commons Attribution License, which permits unrestricted use, distribution and reproduction in any medium, provided the original author and source are credited. 
as modulation of cytokine production. Aged garlic extract has shown a variety of anti allergic and antitumor effects through tumor cell growth inhibition and chemopreventive effects as reported by Kyo et al [7]. There was significant reduction of IL-12 production and increase in IL-10 production with low concentration garlic extract [8]. It is also reported that with the extract there is significant reduction with TNF- $\alpha$ (tumor necrosis factor), IL$1 \alpha$, IL-6, IL-8, T cell interferon-gamma (IFN- $\gamma$ ), IL-2 [9].

Curcuma longa, a perennial herb commonly cultivated in India. The rhizome of $\mathrm{C}$. longa has numerous medicinal uses including analgesic, anti-inflammatory, wound healing and immunomodulatory activities [10]. The chief constituent of C. longa is curcumin which plays a major role for immunomodulatory activity [11]. Bone marrow cellularity, alpha-esterase positive

cells and macrophage phagocytic activity were enhanced by Curcumin administration [12]. Numerous evidence suggest that curcumin can modulate both the proliferation and therefore the activation of T cells [13]. It has been reported that curcumin inhibits the proliferation induced by PMA and anti-CD28 antibodies or that induced by PHA of T lymphocytes isolated from healthy donors [14]. It can also suppress the phytohemagglutinin-induced proliferation of human peripheral blood mononuclear cells and inhibit IL-2 expression and NF- $x$ B39 [15]

The mechanisms of honey's immunomodulatory properties were unknown but few authors suggested that high levels of hydrogen peroxide in honey may have induced a negative feedback effect on the production of ROIs by the MM6 cells [16]. Increased production of the cytokines TNF- $\alpha$, interleukin-1 (IL-1 $\beta$ ) and IL-6 by MM 6 cells and human blood monocytes have also been reported [17].

Spirulina, a cyanobacteria belonging to the Oscillatoriaceae, has been used since the past as a source of protein and vitamins [18]. The most common species used in the field of medicine are Spirulina platensis and Spirulina maxima [19]. Spirulina have shown to have antioxidant, immunomodulatory, anti-inflammatory, anticancer, anti-viral, and antibacterial effects and is a powerful stimulator of the immune system by increasing the stimulation of IL-1 $\beta, I L-4$, and interferon (IFN)- $\gamma$ [20]. Phycocyanin which is a component of spirulina have shown to increase the secretion of TNF- $\alpha$, IL- $1 \beta$, and IL- 6 by J774A cells, along with the expression of IL-1 $\beta$ and COX-2 proteins [21].

Thus the aim of the study is to perform in vitro analysis to assess the combined immunomodulatory effect of garlic, turmeric, honey and spirulina.

\section{Materials And Methods}

The materials used in this study includes extracted compounds containing $1 \mathrm{~g}$ of each herbals garlic, turmeric, honey and spirulina, these materials were acquired from authentic biomaterial sellers. A beaker of $100 \mathrm{~mL}$ of distilled water is taken and extract of $1 \mathrm{~g}$ garlic, turmeric, honey and spirulina is mixed together, these extracts were then heated for 15 minutes, filtered and again heated until the solution is reduced to about $5 \mathrm{~mL}$ of concentration, in order to reduce the water and increase the concentration of extraction followed by cooling down of the prepared extract [figure 1].

The prepared extract of garlic, turmeric, honey and spirulina is subjected to 2, diphenyl 1-picryl- hydrazyl- hydrate assay (DPPH). The extract is first subjected to 5 different concentrations of 10 $\mu \mathrm{L}, 20 \mu \mathrm{L}, 30 \mu \mathrm{L}, 40 \mu \mathrm{L}, 50 \mu \mathrm{L}$ in solution containing $1 \mathrm{~mL}$ of $\mathrm{DPPH}$, the solution is maintained at a room temperature for 10 mins, this is followed by boiling of the contents at 55 degree Celsius for $10-15$ mins, this solution is then subjected to spectrophotometry for inhibition level analysis. The reduction in the quantity of DPPH free radicals was assessed dependent on the absorbance at 517nm [Figure 2].

Ferric reducing antioxidant power assay (FRAP) was then performed. FRAP solution $(3.6 \mathrm{~mL})$ was added to distilled water $(0.4$ $\mathrm{ml})$ and incubated at $37 \mathrm{C}$ for $5 \mathrm{~min}$. Then this solution mixed with $10 \mu \mathrm{L}, 20 \mu \mathrm{L}, 30 \mu \mathrm{L}, 40 \mu \mathrm{L}, 50 \mu \mathrm{L}$ concentration of prepared extract of garlic, turmeric, honey and spirulina and incubated at $37 \mathrm{C}$ for $10 \mathrm{~min}$. The absorbance of reaction mixture was measured at $593 \mathrm{~nm}$ [Figure 3].

H2O2 assay was performed by Halliwell method. All solutions were prepared freshly $1.0 \mathrm{~mL}$ of the reaction mixture contained

Figure 1. Final prepared extract of Garlic, turmeric, honey and spirulina.

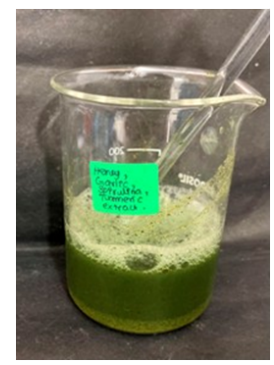

Figure 2. DPPH assay performed in microtiter plate at concentrations of $10 \mu \mathrm{L}, 20 \mu \mathrm{L}, 30 \mu \mathrm{L}, 40 \mu \mathrm{L}, 50 \mu \mathrm{L}$.

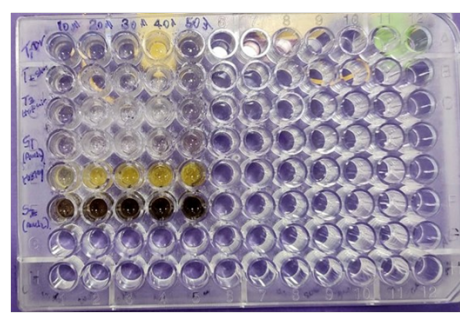


$100 \square \mathrm{l}$ of $28 \mathrm{mM}$ of 2-deoxy-2-ribose (dissolved in phosphate buffer $\mathrm{Ph} 7.4$ ), $500 \square$ l solution of various concentration of the extract (10-50 $\square \mathrm{l}), 200 \square \mathrm{l}$ of $200 \square \mathrm{m} \mathrm{Fecl} 3$ and $1.04 \mathrm{mM}$ EDTA $(1: 1 \mathrm{v} / \mathrm{v}), 100 \square \mathrm{l} \mathrm{H} 2 \mathrm{O} 2(1.0 \mathrm{mM})$ and $100 \square \mathrm{l}$ ascorbic acid $(1.0 \mathrm{mM})$. After an incubation period of 1 hour at $37 \mathrm{c}$ the extent of deoxyribose degradation was measured by TBA reaction and the absorbance was measured at 532nm [Figure 4].

\section{Results And Discussion}

The results of the study has shown that the prepared extract of garlic, turmeric, honey and spirulina has a better inhibition action in DPPH , FRAP, H2O2 assay analysis. Spectrophotometry readings of DPPH, FRAP, H2O2 assay shows that the absorbance range was close to the standard(vitamin C) and also at 50 of garlic, turmeric, honey and spirulina have more absorption percentage of $72.1 \%, 94.6 \%$ and $67.9 \%$ respectively [Figure 5,6,7].

Plants of the Allium are known for the presence of organosulfur compounds, which possess interesting biological and pharmacological properties. Among these, garlic (Allium sativum) is one among the foremost widely used ones. When extracted and isolated, these compounds exhibit a broad spectrum of beneficial effects against microbial infections and are also known for cardioprotective, anticancerigenic, immunomodulatory and anti inflammatory activity [22-26]. Effect of garlic on immune system components is due to the proinflammatory state which is related to the induction of inflammatory mediators, the oxidative stress, and the activation of different immune cells[8]. It is a promising candidate for maintaining the homeostasis of the immune system [27]. Thiacremonone, a sulfur compound which is isolated from garlic, were found to inhibit iNOS expression and NO. production by blocking $\mathrm{NF} \varkappa \mathrm{B}$ activity in vitro and also ameliorate inflammatory responses and arthritic reactions in acute and chronic edema in arthritic animal models as reported by Ban J et al [28]. Badr G $\mathrm{M}$ et al reported that it exerts antioxidant action by scavenging reactive oxygen species (ROS) and enhancing cellular antioxidant enzymes such as superoxide dismutase, catalase, and glutathione peroxidase and also an important source of antioxidants due to phytochemicals such as DAS and SAMC [29]. A study done by You H.S et al demonstrates that garlic extract suppressed LPSinduced TLR4 dimerization, suggesting this inhibition to be one among the mechanisms for the garlic anti-inflammatory activity [27]. Thus it shows that garlic can modulate inflammatory responses through the suppression of TLR activation leading to the inhibition of NFxB and COX-2 activation and iNOS expression.

Turmeric constituents include three curcuminoids such as Curcumin, demethoxycurcumin and bisdemethoxycurcumin. Cir-

Figure 3. FRAP assay performed in test tubes for the prepared extract at concentrations of $10 \mu \mathrm{L}, 20 \mu \mathrm{L}, 30 \mu \mathrm{L}, 40 \mu \mathrm{L}, 50 \mu \mathrm{L}$.

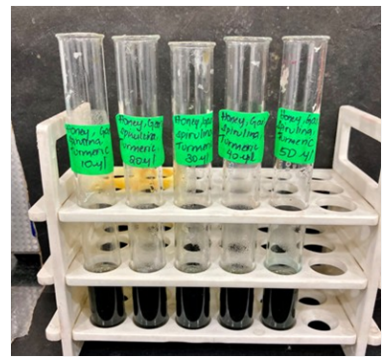

Figure 4. H2O2 assay performed in test tubes for the prepared extract at concentrations of $10 \mu \mathrm{L}, 20 \mu \mathrm{L}, 30 \mu \mathrm{L}, 40 \mu \mathrm{L}, 50 \mu \mathrm{L}$.

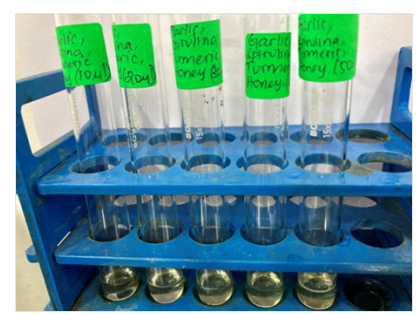

Figure 5. Using DPPH assay the absorbance of reaction mixture measured at $517 \mathrm{~nm}$.

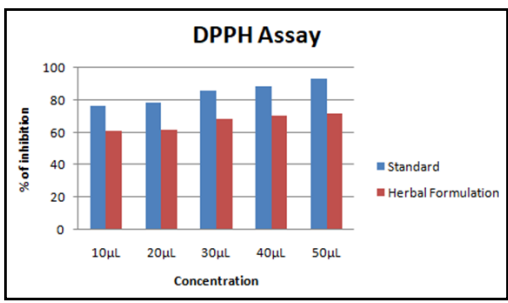

Figure 6. Using FRAP assay the absorbance of reaction mixture measured at 593nm..

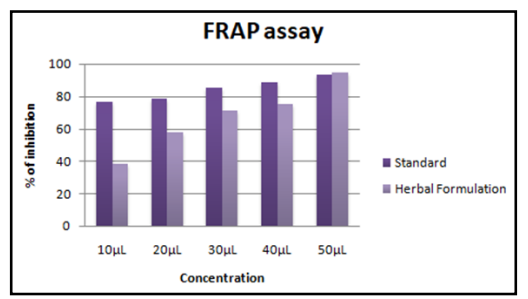


Figure 7. Using $\mathrm{H} 2 \mathrm{O} 2$ assay the absorbance of reaction mixture measured at $532 \mathrm{~nm}$.

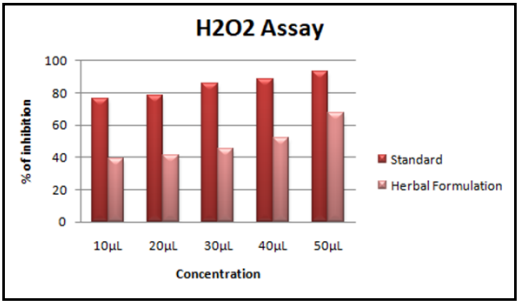

cumin has the ability to suppress cellular transformation, proliferation, invasion, angiogenesis and metastasis [30]. Khar A et al reported that induction of stress response rendered tumor cell lines immune to curcumin-mediated apoptosis, which was dependent on ROS intermediates [31]. The dose of curcumin determines ROS generation capacity, intracellular ATP levels, apoptosis or necrosis in osteoblast [32]. In a study done by Limtrakul et al curcumin modulates the reversal of multi-drug resistance [33]. Curcumin plays a direct role in the treatment of varied autoimmune disorders and it inhibits IL-12 mediated Th1dependent neuronal demyelination in murine model of multiple sclerosis by targeting Janus kinase 2, tyrosine kinase 2, STAT3 and STAT4 as reported by Natarajan $C$ et al [34]. It also enhances the clearance of amyloid- $\beta$ (plaques) within the brain by M $\phi$ s (macrophages) in Alzheimer's patients [35]. Under severe conditions of infection, curcumin attenuated LPS-mediated endotoxemia [36]. Curcumin targets TLR-adapter-MD-2 and inhibits homodimerization of TLR4 to exhibit anti-inflammatory response $[37,38]$. Cho JW et al in a study have reported that Curcumin has shown to attenuate the expression of IL- $1 \beta$, IL- 6 , and cyclin $\mathrm{E}$ in TNF- $\alpha$ treated human keratinocytes [39]. It also prevents atrophic arthritis, by inducing apoptosis and inhibiting prostaglandin E2 production in synovial fibroblasts of atrophic arthritis patients [40, 41]. It controls allergic responses by attenuating Th2 inflammatory responses [42]. Cooper and Burton suggest that honey may be able to reduce inflammation by quenching free radicals in an inflammatory site [16]. Chepulis and Francis reported that honey containing high levels of methylglyoxal (MGO) have contradictory effects on TNF- $\alpha$ production by neutrophils [43]. Spirulina fusiformis ( $1 \mathrm{~g} /$ day for 12 months) had chemopreventive activity in reversing oral leukoplakia in pan tobacco chewers in Kerala, India as reported by Mathew et al [44].

\section{Conclusion}

The advantage of these natural products is the higher bioavailability, ease of use and most importantly lesser adverse effects. The present study was done to assess the combined immunomodulatory effect of garlic, turmeric, honey and spirulina using modern technique and a spectrophotometry was used for analysis. It showed significant antioxidant, immunomodulatory properties and higher zone of inhibition when compared to a standard. With more future studies this extract can be used as an alternative to other commercially available drugs in the form of in situ gel for immune mediated mucocutaneous disorders.

\section{References}

[1]. Catanzaro M, Corsini E, Rosini M, Racchi M, Lanni C. Immunomodulators Inspired by Nature: A Review on Curcumin and Echinacea. Molecules. 2018 Oct 26;23(11):2778. PubmedPMID: 30373170.

[2]. Sell S, Max EE, Berkower I. Immunology, immunopathology and immunity. Washington, DC: ASM press; 2001 Apr.
[3]. Fleit HB. Kuby Immunology. Richard A. Goldsby, Thomas J. Kindt, Barbara A. Osborne [Internet]. Vol. 76, The Quarterly Review of Biology. 2001. p. 126-126.

[4]. Houghton PJ, Mukherjee PK, editors. Evaluation of herbal medicinal products: perspectives on quality, safety and efficacy. London: Pharmaceutical press; 2009.

[5]. Mukherjee PK, Venkatesh M, Gantait A. Ayurveda in Modern Medicine: Development and Modification of Bioactivity In: Comprehensive Natural Products Chemistry.

[6]. Mukherjee PK, Nema NK, Venkatesh P, Debnath PK. Changing scenario for promotion and development of Ayurveda--way forward. J Ethnopharmacol. 2012 Sep 28;143(2):424-34. PubmedPMID: 22885133.

[7]. yo E, Uda N, Kasuga S, Itakura Y. Immunomodulatory effects of aged garlic extract. J Nutr. 2001 Mar;131(3s):1075S-9S. pubmedPMID: 11238820. https://pubmed.ncbi.nlm.nih.gov/11238820/

[8]. Arreola R, Quintero-Fabián S, López-Roa RI, Flores-Gutiérrez EO, ReyesGrajeda JP, Carrera-Quintanar L, et al. Immunomodulation and anti-inflammatory effects of garlic compounds. J Immunol Res. 2015;2015:401630. PubmedPMID: 25961060.

[9]. Hodge G, Hodge S, Han P. Allium sativum (garlic) suppresses leukocyte inflammatory cytokine production in vitro: potential therapeutic use in the treatment of inflammatory bowel disease. Cytometry. 2002 Aug 1;48(4):20915. PubmedPMID: 12210145.

[10]. Bagad AS, Joseph JA, Bhaskaran N, Agarwal A. Comparative Evaluation of Anti-Inflammatory Activity of Curcuminoids, Turmerones, and Aqueous Extract of Curcuma longa. AdvPharmacol Sci. 2013;2013:805756. PubmedPMID: 24454348.

[11]. Rahmani AH, Alsahli MA, Aly SM, Khan MA, Aldebasi YH. Role of Curcumin in Disease Prevention and Treatment. Adv Biomed Res. 2018 Feb 28;7:38. PubmedPMID: 29629341.

[12]. Jagetia GC, Aggarwal BB. "Spicing up" of the immune system by curcumin. J ClinImmunol. 2007 Jan;27(1):19-35. PubmedPMID: 17211725.

[13]. Bose S, Panda AK, Mukherjee S, Sa G. Curcumin and tumor immune-editing: resurrecting the immune system. Cell Div. 2015 Oct 12;10:6. PubmedPMID: 26464579.https://pubmed.ncbi.nlm.nih.gov/26464579/

[14]. Ranjan D, Chen C, Johnston TD, Jeon H, Nagabhushan M. Curcumin inhibits mitogen stimulated lymphocyte proliferation, NFkappaB activation, and IL-2 signaling. J Surg Res. 2004 Oct;121(2):171-7. PubmedPMID: 15501456.

[15]. Yadav VS, Mishra KP, Singh DP, Mehrotra S, Singh VK. Immunomodulatory effects of curcumin. Immunopharmacology and immunotoxicology. 2005 Jan 1;27(3):485-97.

[16]. McLoone P, Warnock M, Fyfe L. Honey: an immunomodulatory agent for disorders of the skin. Food and Agricultural Immunology. 2016 May 3;27(3):338-49.

[17]. Tonks AJ, Cooper RA, Jones KP, Blair S, Parton J, Tonks A. Honey stimulates inflammatory cytokine production from monocytes. Cytokine. 2003 Mar 7;21(5):242-7. PubmedPMID: 12824009.

[18]. Somchit MN, Mohamed NA, Ahmad Z, Zakaria ZA, Shamsuddin L, Omar-Fauzee MS, et al. Anti-inflammatory and anti-pyretic properties of Spirulinaplatensis and Spirulinalonar: a comparative study. Pak J Pharm Sci. 2014 Sep;27(5):1277-80. PubmedPMID: 25176383.

[19]. Soheili M, Khosravi-Darani K. The potential health benefits of algae and micro algae in medicine: a review on Spirulinaplatensis. Current Nutrition \& Food Science. 2011 Nov 1;7(4):279-85.

[20]. Finamore A, Palmery M, Bensehaila S, Peluso I. Antioxidant, Immunomodulating, and Microbial-Modulating Activities of the Sustainable and Ecofriendly Spirulina. Oxid Med Cell Longev. 2017;2017:3247528. PubmedPMID: 28182098.

[21]. Chen HW, Yang TS, Chen MJ, Chang YC, Eugene I, Wang C, et al. Purification and immunomodulating activity of C-phycocyanin from Spirulinaplatensis cultured using power plant flue gas. Process Biochemistry. 2014 Aug 1;49(8):1337-44.

[22]. Salman H, Bergman M, Bessler H, Punsky I, Djaldetti M. Effect of a garlic derivative (alliin) on peripheral blood cell immune responses. Int J Immu- 
nopharmacol. 1999 Sep;21(9):589-97. PubmedPMID: 10501628.

[23]. Reinhart KM, Talati R, White CM, Coleman CI. The impact of garlic on lipid parameters: a systematic review and meta-analysis. Nutr Res Rev. 2009 Jun;22(1):39-48. PubmedPMID: 19555517.

[24]. Eilat-Adar S, Sinai T, Yosefy C, Henkin Y. Nutritional recommendations for cardiovascular disease prevention. Nutrients. 2013 Sep 17;5(9):3646-83. PubmedPMID: 24067391.

[25]. Khatua TN, Adela R, Banerjee SK. Garlic and cardioprotection: insights into the molecular mechanisms. Can J PhysiolPharmacol. 2013 Jun;91(6):44858. PubmedPMID: 23746107.

[26]. Fridman S, Sinai T, Zilberg D. Efficacy of garlic based treatments against monogenean parasites infecting the guppy (Poeciliareticulata (Peters)). Vet Parasitol. 2014 Jun 16;203(1-2):51-8. PubmedPMID: 24598083.

[27]. You S, Nakanishi E, Kuwata H, Chen J, Nakasone Y, He X, et al. Inhibitory effects and molecular mechanisms of garlic organosulfur compounds on the production of inflammatory mediators. MolNutr Food Res. 2013 Nov;57(11):2049-60. PubmedPMID: 23766070.

[28]. Banchereau J, Briere F, Caux C, Davoust J, Lebecque S, Liu YJ, et al. Immunobiology of dendritic cells. Annu Rev Immunol. 2000;18:767-811. PubmedPMID: 10837075.

[29]. Badr GM, Al-Mulhim JA. The protective effect of aged garlic extract on nonsteroidal anti-inflammatory drug-induced gastric inflammations in male albino rats. Evid Based Complement Alternat Med. 2014;2014:759642. PubmedPMID: 24876878.

[30]. Lee WH, Loo CY, Bebawy M, Luk F, Mason RS, Rohanizadeh R. Curcumin and its derivatives: their application in neuropharmacology and neuroscience in the 21st century. CurrNeuropharmacol. 2013 Jul;11(4):338-78. PubmedPMID: 24381528.

[31]. Khar A, Ali AM, Pardhasaradhi BV, Varalakshmi CH, Anjum R, Kumari $\mathrm{AL}$. Induction of stress response renders human tumor cell lines resistant to curcumin-mediated apoptosis: role of reactive oxygen intermediates. Cell Stress Chaperones. 2001 Oct;6(4):368-76. PubmedPMID: 11795474

[32]. Chan WH, Wu HY, Chang WH. Dosage effects of curcumin on cell death types in a human osteoblast cell line. Food ChemToxicol. 2006 Aug;44(8):1362-71. PubmedPMID: 16624471.

[33]. Limtrakul P. Curcumin as chemosensitizer. Adv Exp Med Biol. 2007;595:269-300. PubmedPMID: 17569216.

[34]. Natarajan C, Bright JJ. Curcumin inhibits experimental allergic encephalo- myelitis by blocking IL-12 signaling through Janus kinase-STAT pathway in T lymphocytes. J Immunol. 2002 Jun 15;168(12):6506-13. PubmedPMID: 12055272.

[35]. Zhang L, Fiala M, Cashman J, Sayre J, Espinosa A, Mahanian M, et al. Curcuminoids enhance amyloid-beta uptake by macrophages of Alzheimer's disease patients. J Alzheimers Dis. 2006 Sep;10(1):1-7. PubmedPMID: 16988474.

[36]. Chen HW, Kuo HT, Chai CY, Ou JL, Yang RC. Pretreatment of curcumin attenuates coagulopathy and renal injury in LPS-induced endotoxemia. J Endotoxin Res. 2007;13(1):15-23. PubmedPMID: 17621542.

[37]. Gradisar H, Keber MM, Pristovsek P, Jerala R. MD-2 as the target of curcumin in the inhibition of response to LPS. J Leukoc Biol. 2007 Oct;82(4):96874. PubmedPMID: 17609337.

[38]. Youn HS, Saitoh SI, Miyake K, Hwang DH. Inhibition of homodimerization of Toll-like receptor 4 by curcumin. BiochemPharmacol. 2006 Jun 28;72(1):62-9. PubmedPMID: 16678799.

[39]. Cho JW, Lee KS, Kim CW. Curcumin attenuates the expression of IL-1beta, IL-6, and TNF-alpha as well as cyclin E in TNF-alpha-treated HaCaT cells; NF-kappaB and MAPKs as potential upstream targets. Int J Mol Med. 2007 Mar;19(3):469-74. PubmedPMID: 17273796.

[40]. Funk JL, Oyarzo JN, Frye JB, Chen G, Lantz RC, Jolad SD, et al. Turmeric extracts containing curcuminoids prevent experimental rheumatoid arthritis. J Nat Prod. 2006 Mar;69(3):351-5. PubmedPMID: 16562833.

[41]. Park C, Moon DO, Choi IW, Choi BT, Nam TJ, Rhu CH, et al. Curcumin induces apoptosis and inhibits prostaglandin $\mathrm{E}(2)$ production in synovial fibroblasts of patients with rheumatoid arthritis. Int J Mol Med. 2007 Sep;20(3):365-72. PubmedPMID: 17671742.

[42]. Kurup VP, Barrios CS, Raju R, Johnson BD, Levy MB, Fink JN. Immune response modulation by curcumin in a latex allergy model. ClinMol Allergy. 2007 Jan 25;5:1. PubmedPMID: 17254346.

[43]. Chepulis LM, Francis E. An initial investigation into the anti-inflammatory activity and antioxidant capacity of alpha-cyclodextrin-complexedManuka honey. J Complement Integr Med. 2012 Sep 24;9:Article 25. PubmedPMID: 23023642.

[44]. Mathew B, Sankaranarayanan R, Nair PP, Varghese C, Somanathan T, Amma BP, et al. Evaluation of chemoprevention of oral cancer with Spirulinafusiformis. Nutr Cancer. 1995;24(2):197-202. PubmedPMID: 8584455. 